\title{
South Africa reforms university funding
}

[CAPE TOWN] The South African government has proposed a number of mechanisms for bringing the growth in student numbers into line with the country's manpower requirements. They include completely restructuring the government's formula for calculating university subsidies.

In particular, the government wants to separate the state funding of universities' research and teaching components. Research funds will be earmarked, as will funds for student financial support and those for redressing past imbalances between institutions.

The government's plans, contained in a draft white paper (policy document) published last month, also suggest that funding for undergraduate teaching should be allocated on the basis of fixed subsidies per degree place in each discipline, varying according to the costs of training a student in that discipline.

But it is unclear whether places will be allocated at faculty level or at the level of the particular programmes set to replace the current system of major subjects.

The state will set a national total for the number of subsidized places in each discipline, and individual institutions will negotiate their share of places for a three-year cycle through a Council on Higher Education (CHE). Research funds will be linked to the allocation of postgraduate places, and will be commensurate with training costs.

These funds will be allocated on the basis of existing research capacity and on the need for institutional development. But it is unclear how these two criteria will be assessed.

The new proposals contrast sharply with the present funding system, set up in 1982, which allocates funding using a formula incorporating student enrolment and success rates, but with different weighting for arts- and science-based courses, and for undergraduate and postgraduate students.

The current formula also includes a measure for research output. This will not feature in the new formula, but will be taken into account when student places are reallocated at the end of each three-year cycle.

With no limits on student numbers in the various disciplines, the present system has led to undirected growth, particularly in the arts and social sciences. The government acknowledges the resulting imbalance in the qualifications of graduates, but indicates that, although future growth will attempt to increase enrolment in science-based programmes, cuts are not envisaged in other disciplines, as an overall growth in student numbers is anticipated.

The draft white paper does not provide for the incorporation of colleges of education, nursing and agriculture into universities and technikons, as suggested last year by the
National Commission on Higher Education (see Nature 384, 13-14; 1996), although it does propose that they are administered under one system.

Universities are relieved that they will be allowed to retain their own admissions criteria, and not be required to work through a central admissions office. Hugh Amoore, registrar at the University of Cape Town, describes the draft white paper as a "great improvement" on the green paper (consultation document). In particular, he welcomes the concept of a three-year funding cycle, as that will help planning.

But Amoore and others warn that the success of the changes is predicated on competence at ministerial, civil servant and CHE level. They express concern, for example, that the senior post responsible for higher education in the Department of Education is vacant.
A draft Higher Education Bill, providing for the establishment of the CHE, has also been published, and should be put to parliament during this session. Institutions have until 23 May to respond to both, and it is hoped that the council will be appointed by October.

Universities are likely still to be funded according to the old formula in 1998, although this may be combined with the distribution of some earmarked funds. The new system is destined to be in operation from 2000.

Meanwhile, the continued reduction in South Africa's university subsidy under the old formula, announced in March, has led to further student unrest. Four universities, including the Universities of the North and Fort Hare closed down, with students protesting at a decision to exclude those who were unable to pay fees.

Michaelcherry

\section{Researchers pin hopes on international sources}

[CAPE TOWN] As access of

university researchers in

South Africa to government

funds declines, many are

hoping that their salvation

lies in international sources

of funding.

This month, the European

Union (EU) agreement on

scientific and technological

cooperation with South

Africa, which was signed last

December, takes effect, and

several United Nations

agencies have recently

established offices in South

Africa and are assisting with

research development.

The agreement with

Europe enables South Africa

to participate in the union's

fourth Framework research

programme, where it is

classified as a developing

country. Europe provides 50

per cent of the costs of joint

research programmes by

groups with participants from

two of its member states and

at least one developing

country.

One of the first South

Africans to receive EU funds, Karen Esler of the botany department at the University of Stellenbosch, says that this will provide "a tremendous boost" to her research on arid ecosystems.
The United Nations

Educational, Scientific and

Cultural Organization

(Unesco) last year

established an office in

Pretoria to serve southern

Africa. According to its

science and technology

adviser, Benjamin Ntim, it is

particularly interested in

developing a programme to

address the problem of

inadequate laboratory

equipment in schools, and it

may enlist the help of other

international agencies.

South African

researchers are now eligible

to apply for funds from

Unesco's regular programme,

in any field of science, or for

specially earmarked funds

for research on

biotechnology, man and the

biosphere, and hydrology. As

a result of South Africa

joining the organization's

Intergovernmental

Oceanographic Commission,

its researchers are now

eligible for sponsorship to

attend its meetings and

training workshops.

The World Bank has also recently opened an office in Pretoria, and is encouraging research projects that coincide with its mission of "a sustained attack on poverty". The bank's deputy

representative, Junaid

Ahmad, emphasizes the

need to engage local

researchers in programmes

focusing on economic issues and behavioural changes.

The Global Environment

Facility, administered by the bank and the United Nations Development Programme, is considering several applications from South African research groups.

Last month the Benefit

project was launched

(Benguela Environment

Fisheries Interaction Training),

with substantial aid from

Norway and Germany. This

is concerned with developing

an understanding of the

Benguela fisheries on the

west coast of South Africa,

Angola and Namibia, and of

procedures for stock

assessment.

Among the benefits for

scientists from these

countries will be access

provided by the European

partners to ships' time, which

is expensive. "Nothing much

has happened yet, but at last

things are starting to

happen," says John Field,

president of South Africa's

Scientific Committee on

Oceanic Research.

M.C. 